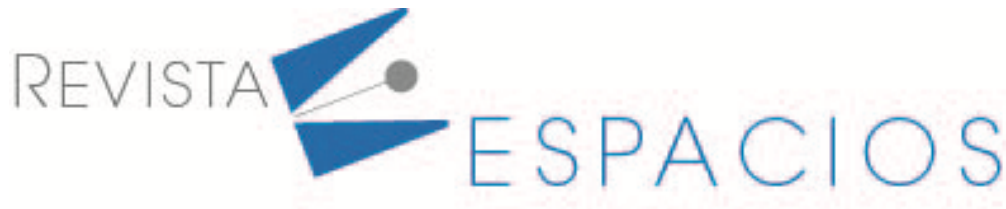

\title{
Digital society and human with soft skills
}

\section{Sociedad digital y humana con habilidades suaves}

\author{
PLUZHNIKOVA, Natalya N. ${ }^{1}$
}

\begin{abstract}
The digitalization of society in the modern world is becoming the main carrier and source of social change. In conditions of instability and socio-political tension, education becomes extremely important, which will be united by common tasks and development prospects. In these conditions, it becomes necessary to have high-quality training of specialists with soft skills.
\end{abstract}

Keywords: Digital society, person, education.

\section{Resumen}

La digitalización de la sociedad en el mundo moderno se está convirtiendo en el principal portador y fuente de cambio social. En condiciones de inestabilidad y tensión sociopolítica, la educación adquiere suma importancia, que estará unida por tareas comunes y perspectivas de desarrollo. En estas condiciones, se hace necesaria una formación de alta calidad de especialistas con habilidades blandas.

Palabras clave: Sociedad digital, persona, educación.

\section{Introduction}

In the context of total digitalization, education is becoming an important determinant that allows a person, based on their competencies and skills, to build new models of interpersonal interaction and learning. Today, education is faced with qualitatively new challenges, which, in our opinion, should include the following challenges:

- Digitalization of education, which creates objective prerequisites for understanding the need to create common mechanisms of international interaction in the field of state, social and cultural policy. This is due to the fact that digitalization of education carries a number of risks, including technical ones: violation of information confidentiality, information intrusions, and hacker attacks (Sharma, Karforma, 2012);

- Socio-anthropological challenges. Education becomes a strategic basis for the development of modern society and a marker of changes taking place with a person and his worldview. Therefore, today it is extremely important to train a specialist with a broad outlook on the world, possessing not only knowledge in the field of his specific specialization, but also soft skills: the skills of socio-cultural cooperation and interaction between people. The answer to these challenges can be "the orientation of education and training on basic spiritual values and human needs, which will become a response to the deterministic challenges of digital reality. The forms of such a response can be creativity, innovative approaches, and ways of developing a person's thinking. It is no

\footnotetext{
${ }^{1}$ PhD. Department of Philosophy, History and Intercultural Communications. Moscow Technical University of Informatics and Communications. Russia. email: n.n.pluzhnikova@mtuci.ru
} 
coincidence that today many experts talk about the need to develop the so-called "flexible thinking", the acquisition and development of soft skills in the learning process "(Pluzhnikova, 2021).

Such a specialist must understand not only the national and cultural characteristics of his country, but also the specifics of historical interaction between countries united by common tasks in the field of state, economic and cultural policy. It is the training of such a specialist that, in our opinion, should become the main goal of cooperation between states at the digital level. So, for example, in 2021, the Eurasian Economic Union proposed to develop an agreement on scientific and technical cooperation: "Consolidation in the field of ICT is one of the conditions for speedy digitalization. Today, an initiative has been approved to develop an international treaty on scientific and technical cooperation in the Eurasian Economic Union" (EAEU proposed to develop international treaty on scientific and technical, 2021).

It is no secret that today education continues to be conservative in terms of "point", narrow specialization. However, Eurasian integration is impossible today without integration in the field of understanding common tasks and development prospects as a single entity in a plural, multipolar whole: Multipolarity or polycentrism implies the formation of political and economic alliances, unions and organizations on a primarily contractual basis that reflect jointly-developed positions of separate countries expressed on the state level, satisfying their national interests and nations' self-identification in the world community. Multipolarity differs in the fact that there are no universal approaches to politics, economy, cultural development, the spread of national customs and beliefs; there is no ambition to "suppress" or impose ideas or ideological determinants on the whole association or union. In other words, national ethnic and social, religious, historical and cultural variety of nations and peoples is perceived as it is, national interests of countries or ethnic groups are not suppressed, state general system values and development priorities are distinguished whose implementation leads to equal interaction of parties thus improving stability of the world community development on the whole. That implies that multipolarity under current conditions can be based upon the participation of separate countries in various associations, unions, and alliances with the purpose of pursuing and carrying out national interests in the world economy and at that regionalization is the dominant factor that enhances the interaction of parties» (Perskaya, 2018).

To implement common strategies in such multipolar cooperation, it is important to train a specialist who will be able to analyze and think systematically. Therefore, today we need a qualitatively new training in the framework of interdisciplinary relations.

System modeling is the creation of a digital environment in which the future specialist will develop soft skills in the main disciplines included in the basic level of preparation for the 1st year in the university education system. It is in the 1st year that a future specialist should form a systemic vision of his future role, an understanding of his skills and competencies, which are necessary not only in a specific job, but also when interacting with other people. Based on the training of these skills, not only the role of the future specialist in the modern world, but also the principles of Eurasian cooperation in the field of education can be revised. What principles, in our opinion, could play a key role in the development of a future specialist with a broad outlook on the world?

1. Competence principle (development of basic skills and soft skills): "Competencies determine the observed behavior that successful employees demonstrate at work. This behavior is the result of the various abilities, skills, knowledge, motivation and traits that an employee may possess. Competencies include knowledge, skills, as well as the ability to use this knowledge and skills "( Beckett, 2018).

2. Value principle (development of moral qualities): "Values in education act as elements of the structure of moral education of students, as the most important components of a person's internal culture, which, expressed in relationships, properties and qualities, determine a person's attitude to society, nature, other people, his 
relatives and himself. A person's moral qualities determine his life position, attitudes and behavioral stereotypes" (Searko, 2020);

3. Content principle (creation of a high-quality individual educational environment for a student and teacher, training of qualified teaching staff);

4. System-forming principle (development of worldview guidelines in terms of understanding common tasks in the field of state, economic and cultural policy).

We put the competence principle in the first place, in which the development of skills, both narrow and soft skills, plays a key role. It is soft skills that will help a person become a "Human": be able to build constructive communication, master communication, show empathy and understanding in relation to other people. In the modern world of economic relations, dominated by individualistic ethics, the principle of competition, not cooperation, is extremely important, in our opinion, empathy. Empathy defines a person's identity and influences his personality. We tend to understand ourselves through the people we spend time with, and we derive our sense of self from the people with whom we have the closest relationships. Empathy helps a person expand their own horizons of thinking and perception of reality. Understanding the other through empathy, through empathy, is the key to successful innovations and an important process that determines the development, the dynamics of thinking.

Putting yourself in the shoes of others and understanding their point of view facilitates communication and business negotiations: "Empathy allows you to use your other person's perspective as a common starting point to influence your point of view. Empathy is important, especially when you disagree with others. It is also easier to empathize when you are similar or when you have common traits with another person. Empathy may not change your opinion of the person, but it can help you value others and relate to them in a different way. Empathy benefits identity, influence, collaboration, and expanded thinking. Empathy in action is about understanding a colleague's problems and offering help. The empathic person always takes the point of view of the team member into account and makes a new recommendation that helps to achieve greater success for the group. As the popular saying goes: people may not remember your actions, but they will remember how you made them feel" (Brower, 2019).

Therefore, another principle follows from the principle of empathy - the value principle. The formation of moral qualities, the upbringing of a person will allow him to organize the world around him - to build a specific environment for interpersonal interaction; therefore the value principle is associated with the implementation of the meaningful principle. The latter will allow building interaction not only at the micro, but also at the macro level, that is, building joint development strategies in the field of state, economic and cultural policy. It is the development of soft skills that we consider one of the fundamental and important tasks in terms of successful Eurasian cooperation.

Soft skills are a concept that is used today to refer to teaching behavioral skills, cross-cultural skills, as opposed to "hard skills" (narrow, subject skills). Various specialists include a set of skills in this concept. But the following classification is closest to us:

1. Ability to build communication and socio-cultural interaction;

2. Skills of self-management: help to effectively control your condition and time. Self-management refers to the ability of a person to consciously and productively manage their behavior, thoughts and emotions. A person with advanced self-management skills knows and understands what to do and how to act in different situations. For example, he knows how to control his anger; how not to be distracted when doing homework to stay focused and learn productively; what you need to do to achieve your goals in activities. 
Self-government also means that a person understands and bears his personal responsibility in various aspects of his life and does everything necessary to fulfill this responsibility. Self-management is associated with what in modern science is called emotional intelligence, since it performs the function of self-regulation, which is supported by the ability to self-awareness, helping a person to create conscious access to his own thoughts, desires and feelings. Only by realizing these things can one begin to control and express them appropriately. If a person has well-developed self-awareness and self-regulation, he will always have ample opportunity to develop self-management skills.

It should be noted that the skill of self-management is important not only for an individual person, but today it is also important in teamwork, joint work. From an organizational point of view, the ability of team members to govern themselves is critical to the effective functioning of the entire organization. Imagine an environment in which most of those who work in it cannot adhere to a task, strategy, and schedule. This would make projects difficult to complete.

Self-management becomes even more important when we talk about empowering people in an organization to be more innovative and resourceful. When each team member understands their responsibilities and what is required to achieve the goals, they can make better decisions and contribute to the achievement of the goals of the team and the organization. What skills are related to self-management? The following can be distinguished: First, the clarity of the fulfillment of the social role. If a person understands his social role in the team, he clearly knows what his responsibilities are and how his capabilities in performing duties can be assessed. Second, alignment of goals: the success of an organization depends on team members working together to achieve a common goal. For this skill to work with a team of self-directed people, each of them must understand the big picture and align their own goals with those of the team. This will allow you to constantly monitor the process of your teamwork. Third, strategic planning: "is the ability to understand what we need to do to achieve the goals of the organization, as well as to set priorities for our own activities" (Munro, 2021).

3. Skills of effective thinking: managing the processes in the head, which help to make life and work more organized, critically assess and analyze situations;

4. Management skills that are required to manage business processes, processes in the field of state, economic and cultural management (Doyle, 2019). The development of digital interaction and human learning is possible through the quality training of a systems-thinking specialist in the field of state, economic and cultural policy in the digital promise.

The condition for high-quality training of such a specialist is the development of soft skills. The development of the latter will be successful by teaching all students using technical means, for example, general skills on a single digital platform - a telegram bot. It contains a knowledge base on various subjects that a student masters in the first year in the system of higher education. This knowledge base is interdisciplinary in nature. Thanks to this, end-to-end, that is, direct systemic teaching of subjects and the development of soft skills will be carried out. This will create a unified information base for the exchange of knowledge in the field.

\section{Methodology}

We analyzed the list of subjects that students of the countries of Russia study in the 1st year of the university. These subjects included subjects of the humanitarian profile: philosophy, sociology, history, foreign language. Further, a separate telegram bot was made for these subjects, and then a combined telegram bot was created, the appeal to which will allow the student to navigate in the interdisciplinary environment. Bots are third-party applications that run inside Telegram. Users can interact with bots by sending those messages, commands, and inline requests. The functions of such bots are varied: 
1. The addressee can freely receive customized notifications and news. A bot can act as a smart newspaper, sending relevant content to recipients as soon as it is published.

2. It integrates easily with other services. The bot can supplement Telegram chats with content from external services, for example Wiki, music services, and data on YouTube services.

3. The bot can help you create your own tools (translations, formatting, your own blog).

4. The bot can offer a wide range of gaming options (from simple arcades and puzzles to 3D shooters and realtime strategy games).

5. Analogs of social services can be created in the bot.

The bot can connect people looking for conversation partners based on common interests or proximity. How do bots work? In fact, Telegram bots are special accounts that do not require an additional phone number to set up. Users can interact with bots in two ways:

1. Send messages and commands to bots by opening a chat with them or adding them to groups.

2. Send thematic requests directly from the input field by typing the username of the bot and the request.

This allows you to send content from embedded bots directly to any chat, group or channel. It is quite interesting to create Telegram bots, and they can open up an opportunity for quickly obtaining any information. Building the back end of such bots requires knowledge of working with various interfaces and can be a daunting task if a person has just entered the world of programming or is short on time.

\section{Results}

What skills will help future specialists to master the telegram bot? We managed to highlight the following soft skills:

1. Focus on solving complex problems requiring practical solutions. This is especially true in terms of state, economic and cultural policy, which is directly related to the needs and interests of people in a particular country;

2. Critical thinking. This skill allows society to be insightful and predict effective international cooperation, to understand the complexity and interdependence of decisions made between countries in the field of international cooperation;

3. A creative approach that allows you to find new ideas and ways to solve the problems facing partners in the field of international cooperation;

4. Ability to build a constructive management policy, which will prepare specialists in the field of public and business management;

5. Effective communication and teamwork skills with people of another country and culture;

6. Emotional intelligence. The qualities that are included in the concept of "emotional intelligence" form the ability to participate and joint sympathy and compassion for other people;

7. The ability to negotiate is important not only for joint business, but also for resolving crisis situations and problems arising in the field of international cooperation. 8. Cognitive flexibility, that is, the ability to switch from one narrow task to another in order to see the general perspective of solving a particular problem. A special advantage of the telegram bot will be the development of soft-skills in students. It will provide a separate option for teaching these skills. 
This option will include:

- Opportunities for creating your own on-line whiteboard in order to learn not only to collect information, but also to share with it, pass it on to other people, and understand how they will perceive this information. Feedback is very important. It will be an online board where you can draw diagrams, graphs, create mind maps, post video and audio fragments, stickers and text blocks, and various images.

- Soft-skills blog - a service for keeping a diary of your own achievements in subjects. This service can be used both for posting ads, and as a kind of didactic material. So, for example, it will be very easy for a student to post on his blog page hotlist (a list of sites on the topic being studied that he found on his own). All you need to create it is to enter a keyword into a search engine, and other participants in the educational process will receive a list of links that the participant in the educational process indicated. Due to this option, not only a single educational space will be formed, but also international cooperation of students and a mentoring system will develop.

- Multimedia Scrapbook - a multimedia draft, which is an option that includes a collection of multimedia resources for the subjects studied. This draft may contain links not only to text files, but also to photographs, audio recordings, films, video clips, and even to today's popular animation and virtual tours. For example, you can do sociology, a tour of primitive society, and philosophy - a tour with modern digital culture.

\section{Conclusions}

The ultimate goal of our research is to help a modern young person become a successful specialist with a systematic, anti-crisis thinking. Therefore, the development of such skills as time management, the skills of promoting one's own business projects and reputation management will be of particular importance in our project in the field of developing soft skills. Through the telegram bot and the options created in it, it is possible to develop general soft-skills among students of the countries of Eurasian cooperation.

What are these skills?

1. Self-study skill, which is not just the assimilation of information, but the understanding of various models of human behavior leading to success in the field of professional activity;

2. Professional Feedback that is, receiving feedback through communication, exchange of ideas and knowledge from colleagues and mentors;

3. Skill of networking, that is, training from professionals. These skills are consolidated through exercises that in the future will not only develop professional competencies, but also educate a person's personal qualities, his moral understanding and moral attitude to professional activity and to other people who are the same professinals in their field in the context of total digitalization of society.

\section{Bibliographic references}

Beckett, S. (2018). What's The Difference Between Skills and Competencies? Retrieved from: https://resources.hrsg.ca/blog/what-s-the-difference-between-skills-and-competencies.

Brower, T. (2019.) Think Empathy Is A Soft Skill? Think Again. Why You Need Empathy. Retrieved from: https://www.forbes.com/sites/tracybrower/2019/06/16/think-empathy-is-a-soft-skill-think-again-whyyou-need-empathy-for-success/?sh=469853cb76d6.

Doyle, A. (2019). Top Management Skills Employers Value With Examples. Retrieved from: https://www.thebalancecareers.com/management-skills-list-2062427. 
EAEU proposed to develop international treaty on scientific and technical (2021). Retrieved from: www.eurasiancommission.org/en/nae/news/Pages/17-02-2021-5.aspx.

Munro, I. (2021). What Is self-management, and how can you improve it? Retrieved from: https://www.betterup.com/blog/what-is-self-management-and-how-can-you-improve-it.

Perskaya, V. (2018). Integration process in the Eurasian Economic Union (EAEU): Interstate relations instead of supranationality under the conditions of multipolarity. Espacios. Vol. 39 (\# 11), page 11. Retrieved from: https://www.revistaespacios.com/a18v39n11/a18v39n11p11.pdf.

Pluzhnikova, N. (2021). Digitalization of education during a pandemic: social challenges and risks. Logos et Praxis. Vol. 20 (\#1). pp. 15-22.

Searko, I, Kalenchuk, T. (2020). Values on Modern Education and Moral Upbringing of the Individual Retrieved from: https://cyberleninka.ru/article/n/values-in-modern-education-and-moral-upbringing-of-theindividual.

Sharma, D., Karforma, S. (2012). Risks and Remedies in E-learning System. International Journal of Network Security and Its Applications. February. pp. 51-59.

Esta obra está bajo una Licencia Creative Commons Attribución-NoCommercial 4.0 International

\section{(cc) BY-NC}

